\title{
THE RELATION BETWEEN THE VASO-MOTOR WAVES AND REACTION TIMES.
}

\section{BY WM. R. WRIGHT, \\ University of Michigan}

The experiments herein recorded are a series of reaction experiments conducted with the view of ascertaining any possible relation existing between the vaso-motor wave and the reaction time of the subject; or, stated in the form of a question, does the reaction time of the subject vary in length in accordance with the rise and the fall of his vaso-motor, or 'TraubeHering,' wave?

The subject was placed in a room separate from the recording apparatus so that all distractions of sight and of sound were reduced to the minimum. He was so seated facing a small table that both of his arms rested easily upon the top of the table. Within the palm of the subject's left hand was fastened a Hallion and Comte plethysmograph, while with the right hand he operated a telegraphic key. To the subject was attached also a Sumner pneumograph, the records of which were taken with the view that they might be of special value in the study of another problem in the future. Although no use was made of these records in this series of experiments, it was found that the markings of the pneumograph could be recorded along with the other records without interfering in any way with the subject's attention to the particular task assigned him.

On the table in front of the subject was a telegraphic sounder. This was screened from his view, and furnished the auditory stimulus to which he reacted by pressing the telegraphic key mentioned above.

All the recording apparatus was placed in the experimenter's room, and was connected by air-tight rubber tubing and insulated wires with the apparatus in the subject's room. The records were taken on two kymographs, one of the horizontal 
type with a traveling carrier, and the other a Zimmermann, of the vertical pattern. The motive power for the revolving drums was furnished by an electric motor, the horizontal drum, $50 \mathrm{~cm}$. in circumference, being so regulated in regard to speed that it made one revolution in 7.8 seconds. By means of graded pulleys the rate of speed of the vertical drum was so adjusted that the surface of the drum moved at a rate equaling the rate of the longitudinal movement of the markers connected with the horizontal drum; but it was found that complete reliance could not be placed upon this adjustment alone, as the least slip of one of the belts made a perceptible change in the rate of the speed of the drums.

The vertical drum received the markings of a LombardPillsbury piston-recorder which was connected by a rubber tube with the plethysmograph, the markings of a Marey tambour connected by a rubber tube with the pneumograph, and also the records of an electric marker so connected with the reaction time-marker of the horizontal kymograph that the beginning of each reaction was written on the vertical drum. Care was taken to keep the three writing points in the same vertical line upon the drum.

On the carrier of the horizontal kymograph were fastened two electric markers, one, connected electrically with a vibrating tuning fork, marked fiftieths of a second, and the other by its deflections marked the reaction period of the subject. At first a tuning fork of 200 double vibrations was used, but this necessitated such rapid revolutions of the drum that the responses came in close rhythmical succession, and the subject responded when he expected them and not to the signal.

On the pulley of the horizontal drum was fastened a metal attachment that automatically closed and kept closed an electric circuit during one half of a revolution of the drum. The electric marker of the vertical drum, the reaction marker of the horizontal drum, the telegraphic sounder and the telegraphic key were so wired together and connected with the automatic circuit closer that the closing of the circuit gave the subject his signal and recorded on both drums the beginning of each reaction; and the pressing of the telegraphic key by the subject 


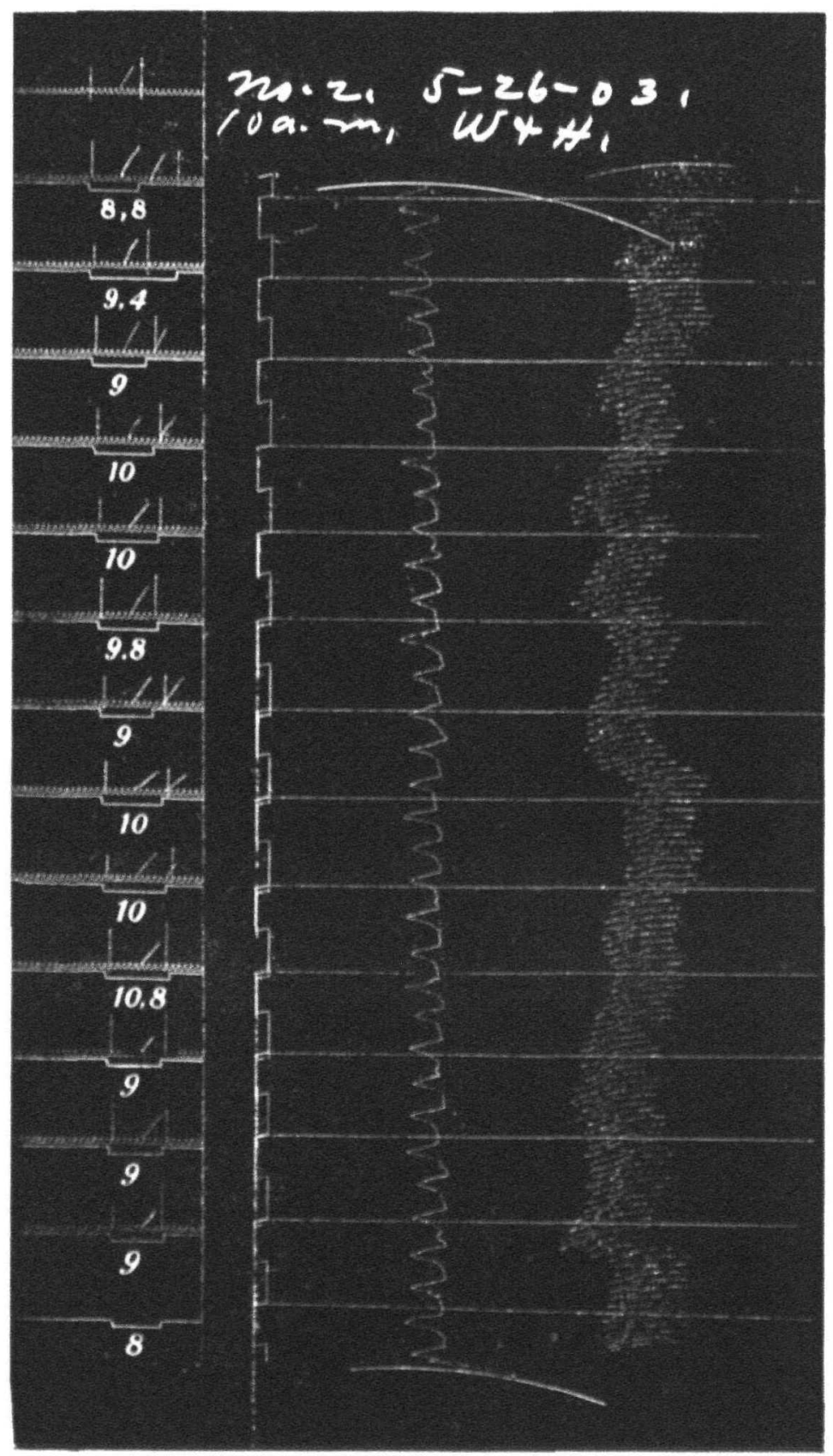


released the reaction marker on the horizontal drum and marked the close of the reaction. For the early experiments the electric current was furnished by storage batteries; but, as these so often proved unsatisfactory, use was finally made of a small dyna-motor which gave a steady reliable current for the tuning fork and the markers.

The only instructions given the subject were that he should keep one position without moving his left hand, and that he should press the telegraphic key with his right hand each time he heard the signal.

Midway between two signals, the release of the telegraphic sounder could be faintly heard, and this became an equivalent for the experimenter's usual 'now.' The length of the time of the revolution of the horizontal drum giving the signals for the reactions was such that the subject was fully able to recover himself before the warning 'now' and thus there was little fluctuation in the degree of his attention throughout a sitting. Thirteen and occasionally fourteen revolutions of the horizontal drum formed one series of experiments; and, after considerable experience, the experimenter was able to secure three series within an hour.

As the sheets of the kymographs were filled, each was fixed by the usual bath; and, for convenience in reading the records, the sheet containing the vaso-motor waves was pasted across the reaction sheet in such a manner that, for an ocular demonstration, the joining of the points marking the close of the reactions formed a series of curves under the vaso-motor curves (see Plate II.). The readings were taken by measuring in fiftieths of a second the length of each reaction. By means of lines drawn perpendicular to the line connecting the points marking the beginning of the reactions, the exact positions of the reactions in time with reference to the vaso-motor waves were found. The lengths of the reactions, or the reactions in seconds, were then grouped into four groups, as to whether the reaction occurred at the base of the vaso-motor wave, on the rise of the wave, at the crest of the wave, or during the fall of the wave. The reaction times of each group were then averaged according to the number of experiments in each group. A correction of .016 
second was made to cover the latent period of the reaction marker.

Five persons served as subjects, Dr. Pillsbury (P.), Mr. Hayden (H.), Mr. Freund (F.), Miss Lee (L.) and Mr. Wright (W.). With the last named, Mr. Hayden conducted the experiments.

Experiments with $P$. were conducted between nine and ten o'clock, a. m., and the table below shows the results obtained.

Base of vaso-motor wave,

Rise of vaso-motor wave,

$$
\begin{aligned}
& \text { Number of } \\
& \text { Experiments }
\end{aligned}
$$

113

65

90

82
Average Reaction Time in Seconas

.170

.186

.194

.187

H.'s reactions were taken at ten o'clock, a. m., two o'clock, p. m., and four o'clock, p. m. on different days. His records, given below, are considered first as forming one series irrespective of time; then each hour is represented as making an independed series.

Base of vaso-motor wave,

Number of
Experiments.

53

63

Crest of vaso-motor wave,

Fall of vaso-motor wave,
42

56
Average Reaction Time in. Seconds

.249

$.26 \mathrm{I}$

.270

.262

Experiments Conducted at Ten O'clock, A. M.

Base of vaso-motor wave, Number of

Average Reaction Experiments. Time in Seconds.

Rise of vaso-motor wave, 14 $.24 I$

Crest of vaso-motor wave, 24 .262

Fall of vaso-motor wave,

Experiments Conducted

Base of vaso-motor wave, Rise of vaso-motor wave, Crest of vaso-motor wave, Fall of vaso-motor wave,

at Two O'Clock, P. M. Number of Experiments.

Average Reaction 7 .249

IO

.252

6

.248

I7

.26 I

Experiments Conducted

Base of vaso-motor wave, Rise of vaso-motor wave, Crest of vaso-motor wave, Fall of vaso-motor wave,

\section{Number of} Experiments

32

29
P. $M$ Average Reaction Time in Seconds .249 .264 .269 .266 
VASO-MOTOR WAVES AND REACTION TIMES. $\quad \mathrm{I}_{3}$

F.'s records, taken at 8 o'clock, a. m., are as follows:

\begin{tabular}{lcc} 
Base of vaso-motor wave, & $\begin{array}{c}\text { Number of } \\
\text { Experiments. }\end{array}$ & $\begin{array}{c}\text { Average Reaction } \\
\text { Tume in Seconds. }\end{array}$ \\
Rise of vaso-motor wave, & 9 & .334 \\
Crest of vaso-motor wave, & 7 & .342 \\
Fall of vaso-motor wave, & 8 & .389 \\
\hline
\end{tabular}

L.'s record, taken at 2 o'clock, p. m., are as follows :

Base of vaso-motor wave, Number of
Arperments.

Rise of vaso-motor wave, 13

.273

Crest of vaso-motor wave,

Io $\quad .282$

Fall of vaso-motor wave,

19.293

$17 \quad .284$

W.'s hours corresponded with H.'s and are similarly reported.

Entire Series of Experiments.

$\begin{array}{lcc}\text { Base of vaso-motor wave, } & \begin{array}{c}\text { Number of } \\ \text { Experimeuts }\end{array} & \begin{array}{c}\text { Average Reaction } \\ \text { Time in Seconds. }\end{array} \\ \text { Rise of vaso-motor wave, } & \text { II } & .187 \\ \text { Crest of vaso-motor wave, } & 58 & .189 \\ \text { Fall of vaso-motor wave, } & 710 & .201 \\ & 71 & .191\end{array}$

\section{Ten O'clock Series of Experiments.}

$\begin{array}{lcc}\text { Base of vaso-motor wave, } & \begin{array}{c}\text { Number of } \\ \text { Experiments. }\end{array} & \begin{array}{c}\text { Average Reaction } \\ \text { Time in Seconds }\end{array} \\ \text { Rise of vaso-motor wave, } & 40 & .189 \\ \text { Crest of vaso-motor wave, } & 27 & .191 \\ \text { Fall of vaso-motor wave, } & 23 & .208 \\ \end{array}$

\section{Two O'clock Series.}

$\begin{array}{lcc}\text { Base of vaso-motor wave, } & \begin{array}{c}\text { Number of } \\ \text { Experiments. }\end{array} & \begin{array}{c}\text { Arerage Reaction } \\ \text { Timein Seconds. }\end{array} \\ \text { Rise of vaso-motor wave, } & 47 & .190 \\ \text { Crest of vaso-motor wave, } & 15 & .199 \\ \text { Fall of vaso-motor wave, } & 30 & .201 \\ \end{array}$

\section{Four O'clock Series.}

Base of vaso-motor wave,

Numbet of Experiments.

Rise of vaso-motor wave,

Crest of vaso-motor wave,

Fall of vaso-motor wave,
25

I6

35

24
Average Reaction Time in Seconds. .182

.175

.190 .186 
It is to be noted that the reactions followed one another in order at a uniform rate throughout a series of experiments regardless of the position of the vaso-motor wave, and that the subject at all times was ignorant of the relation existing between his reaction time and its relative position with reference to his vaso-motor wave, hence the number of experiments occurring in the different groups, $i . \varepsilon$., base, rise, crest and fall of wave, differed widely.

A single sheet of records showed little constancy in its results, and a slight variation may be noted in the breaking up of the whole number of both H.'s and W.'s experiments into the hour series; F.'s and L.'s experiments are too few to be of any special significance; yet even in these cases there is a decided tendency toward the results plainly seen in connection with the whole number of experiments of P., H. and W. The records of the three last named persons show clearly a difference in the times of the reactions that occur at the time of constricted vaso-motors, at the time of dilated vaso-motors or at points midway.

To review P.'s reactions, we find his reactions the shortest (.I7o sec.) when the blood supply in his hand is at its lowest, and that his reactions are the longest (.194 sec.) when there is a full supply of blood. Between these two points, the reactions are slightly quicker if they occur at the time of the dilating (.186 sec.) than if they occur at the time of the contracting (.187 sec.) of the vaso-motors.

The results of H.'s and W.'s experiments, taken in their entirety as one series for each, agree with the facts already noted in connection with P.'s reaction times; e. g., H.'s are .249 , $.261, .270$ and .262 seconds, and W.'s are .187, .189, .20I and .rgr seconds. These same records when broken up into hour series still show, with one or two slight variations, similar relations. The only real discrepancy in H.'s results is to be seen in the time of his reactions occurring at the crest of the wave, but with this it will be noted that the number of experiments (6) is too small to offset general results. With W.'s hour series but two variations occur, and neither one of these materially changes the general trend of the curve of reaction times established by the greater number of experiments. 
In reply to our query stated in the beginning of our report, we would repeat that the results of the above experiments show that the subject's reactions form a curve, which, in shape, agrees close with the curve of his vaso-motor, or 'Traube-Hering,' wave.

L. M. Patrizi in 1896 (see L'Année Psychologique, Vol. 3, I 897 , p. 359) ${ }^{1}$ conducted a series of experiments similar to the above with the exception that he had the opportunity of taking the plethysmographic record from the brain of his subject and thus write the curve of cerebral volume. His reactions are recorded in only two groups, minimum and maximum volume, or base and crest of vaso-motor wave. In all he secured 244 reactions, I 28 at the crest and II 6 at the base of the wave, and his general average of reaction times shows .3325 seconds for the crest and .345 seconds for the base of the wave - just the opposite of those found in our experiments when the record was taken from the finger.

Notwithstanding the difference found by M. Patrizi in his experiments, he concludes that it is too slight to establish any relation whatever between blood supply and reaction time; whereas our results, conducted upon more subjects and in connection with the blood supply of the hand, do show differences great enough to warrant the assumption that the rate of reaction is related to the 'Traube-Hering' wave.

Were Patrizi more sanguine as to the correctness of his results, it would be interesting to discuss the question of the relation of direction between 'Traube-Hering' of brain and finger; but, as it is, no conclusions on this point can be drawn. sammary.

2Original article, Archivi di Psichiatria, I896. We have seen only the 